\title{
Needs for Restructuring the Health Sector Financing in Nigeria: An Exploratory Comparative Study \\ Popoola Oladayo Timothy*
}

Department of Economics, Ahmadu Bello University, Zaria, Nigeria

\begin{abstract}
Evidence reveals that health outcomes of all nations have improved dramatically globally during the 21st century; however, enormous disparities still exist between Nigeria and other developing countries. For instance, Nigeria has the third highest infant mortality rate in the world after India and Pakistan; while in every single day, Nigeria loses an estimated of 2,300 under-five year olds children which also makes her the second largest contributor to under-five mortality rates worldwide after Republic of Chad. Therefore, this study present exploratory comparative analysis on health sector financing across countries in Africa with emphasize on Nigeria. The trend analysis of the study reveals that the direction of governments' priorities and commitments in terms of health spending and resources devoted to health sectors have led to the glaring disparities in health indicators (life expectancy, infant and under-five mortality rates) with Nigeria lagging behind. The findings of the study further suggest that Nigeria needs to strengthen efforts towards improving health status of her citizens through restructuring her health sector.
\end{abstract}

Keywords: Restructuring; Health sector; Comparative study; Nigeria

\section{Introduction}

In every single day, Nigeria loses an estimated of 2,300 under-five year olds children which makes her the second largest contributor to under-five mortality rates worldwide after Republic of Chad $[1,2]$. Although, the health outcomes of all nations have improved dramatically globally during the $21^{\text {st }}$ century, enormous disparities still exist between Nigeria and other developing countries [2]. For instance, Nigeria has the third highest infant mortality rate in the world after India and Pakistan. The report also showed that nearly $10 \%$ of new-born deaths in the world in 2016 occurred in Nigeria. The nation's infant mortality statistics also remains another major problem compared to neighboring countries like Ghana, Niger and Cameroon.

Notably, the nation's infant mortality rate in 2015 was 69 deaths in every 1,000 live births, while for Ghana, Niger and Cameroon it was 43,57 and 57 per 1,000 live births respectively [3,4]. Worse still, 40,000 women die annually in pregnancy or childbirth, and another 1 to 1.6 million women suffer from serious and permanent disabilities from pregnancy- and birth-related causes [5]. Again, 10\% of the world's maternal mortality happen in Nigeria; while on the average between 100 and 120 women die due to child birth every day. Majority of these maternal deaths occur within the first week of newborn babies reflecting the intimate link between their survival and quality of their welfare during and after pregnancy [6].

The average life expectancy at birth in Nigeria is also merely 53 years in recent years, while it is above 80 years for countries like France, Japan, Singapore, and Hong Kong. For Ghana and Niger, their average life expectancies were 64 and 61 years respectively in 2015. All these perhaps explain why Nigeria was far from reaching the health-related targets of the recent past Millennium Development Goals [7]. Another worrisome issue is the high prevalence of; malaria, cholera, acute hepatitis E, stroke, hypertension, typhoid, meningitis, and all forms of cancer and diseases that causes illnesses in the nation. The foregoing therefore suggests that health outcomes in Nigeria are generally poor as previous studies has also indicated $[8,9]$.

Therefore, the major aim of this study is to present comparative analysis on health sector performances across countries in Africa with Nigeria.

\section{Literature Review}

There are various indicators of health sector performances and its outcomes. This includes mortalities, morbidity, diseases burden statistics, and life expectancy, among many others. Mortality is the number of deaths that occur at a specific time, or from a specific cause. There are various types of mortalities that include infants', underfive and adults' mortalities, due to cholera, malaria, tuberculosis, hypertension, stroke, HIV/AIDS and various forms of cancer. Infant mortality refers to death before the first year of life, for example, the death during the age of 0 to 365 days. Meanwhile, under-five mortality is the death between the first and fifth birthday that is death during ages of 12 to 60 months. In another words, under-five mortality is the death before reaching the fifth years of life.

Several studies have consistently reported a global estimate of 9.7 million under-five deaths globally, where $41 \%$ of these deaths occur in SSA nations including Nigeria. Nigeria loses about 2,300 under-five year olds children daily which makes the country the second largest contributor to child and under-five mortalities worldwide. The World Bank also reveals that under-five mortality rate in Nigeria is 109 per every 1,000 live births in 2015, while majority of these deaths occur within the first week of newborn babies mainly due to complications during pregnancy, delivery and post-delivery; reflecting the intimate link between newborn survival and quality of maternal care during and after pregnancy. Other studies have also shown that child health outcomes are generally poor.

Table 1 shows that in 1975, Rwanda's U5MR was 244.9 deaths per every 1,000 , while Nigeria's U5MR at the same period was 244.3 per 1,000 (which were slightly lower than the Rwanda's). By 1995, the rate

${ }^{*}$ Corresponding author: Popoola Oladayo Timothy, Department of Economics, Ahmadu Bello University, Zaria, Nigeria, Tel: +234659874; E-mail: poladayo@gmail.com

Received May 04, 2018; Accepted June 01, 2018; Published June 06, 2018

Citation: Timothy PO (2018) Needs for Restructuring the Health Sector Financing in Nigeria: An Exploratory Comparative Study. Int J Econ Manag Sci 7: 526. doi: 10.4172/2162-6359.1000526

Copyright: ( 2018 Timothy PO. This is an open-access article distributed under the terms of the Creative Commons Attribution License, which permits unrestricted use, distribution, and reproduction in any medium, provided the original author and source are credited. 


\begin{tabular}{|l|c|c|c|c|c|c|c|c|c|}
\hline & $\mathbf{1 9 7 5}$ & $\mathbf{1 9 8 0}$ & $\mathbf{1 9 8 5}$ & $\mathbf{1 9 9 0}$ & $\mathbf{1 9 9 5}$ & $\mathbf{2 0 0 0}$ & $\mathbf{2 0 0 5}$ & $\mathbf{2 0 1 0}$ & $\mathbf{2 0 1 5}$ \\
\hline Cote d'Ivoire & 201.1 & 166.6 & 154.2 & 152.6 & 152.7 & 145.6 & 128.8 & 109.1 & 92.6 \\
\hline Ghana & 185.9 & 166.2 & 154.6 & 127.4 & 113.4 & 100.7 & 86.5 & 74.7 & 61.6 \\
\hline South Africa & 126.6 & 93.1 & 70.7 & 59.9 & 62.1 & 75.3 & 75.2 & 53.8 \\
\hline Rwanda & 244.9 & 218.2 & 160.1 & 151.8 & 268.3 & 183.8 & 110.7 & 64.1 \\
\hline Nigeria & 244.3 & 214.4 & 209.5 & 212.5 & 207.8 & 186.8 & 158.1 & 130.3 \\
\hline
\end{tabular}

Source: Compiled from World Development Indicator, 2017.

Table 1: Under-five mortality rate in Nigeria compared to other countries.

\begin{tabular}{|c|c|c|c|c|c|c|c|c|c|}
\hline & 1975 & 1980 & 1985 & 1990 & 1995 & 2000 & 2005 & 2010 & 2015 \\
\hline Cote d'Ivoire & 47.7 & 50.7 & 52.6 & 52.6 & 49.5 & 46.7 & 47.7 & 50.1 & 51.9 \\
\hline Ghana & 50.8 & 52.3 & 54.1 & 56.7 & 57.5 & 56.9 & 58.7 & 60.6 & 61.4 \\
\hline South Africa & 54.2 & 56.9 & 59.9 & 62.1 & 61.4 & 55.8 & 51.5 & 54.4 & 57.4 \\
\hline Rwanda & 44.9 & 47.9 & 50.4 & 33.4 & 31.6 & 48.1 & 54.7 & 61.4 & 64.5 \\
\hline Nigeria & 43.4 & 45.5 & 46.3 & 46.1 & 46.1 & 46.6 & 48.6 & 51.3 & 53 \\
\hline
\end{tabular}

Source: Compiled from World Development Indicator, 2017.

Table 2: Average Life Expectancy at birth (total) in Nigeria compared to other Nations.

increased to 268.3 per 1,000 for Rwanda, while Nigeria's rate was still relatively lower at 212.5 per 1,000 . Notably, in 2015, Rwanda's rate decrease to as low as 41.7 mortality in every 1,000 live birth, while U5MR in Nigeria was as high as 108.8 deaths in every 1,000 under-five children in the same period.

For infant mortality rate, evidence reveals that the world has recorded some appreciable progress in reducing global infant mortalities over the recent years due majorly to various action plans, efficient health policies and interventions targeted at various deadly diseases, and other childhood infections which have been major causes of mortalities. However, the situation seems to remain unchanged in SSA countries, as approximately half of infant deaths occur in Africa, despite the region having only one fifth of the world's children population [10]. Unlike other regions of the world, SSA nations including Nigeria are also lagged behind in achieving the recent past MDGs particularly those which are directly affects children health outcomes.

According to a World Bank report infant mortality rate in Nigeria is the second largest in SSA as at 2015 with about 69.4 deaths in every 1,000 live births, while Chad has the highest of 85 deaths per 1,000. WHO (2012) have also shown that on average, an African woman's risk of dying from pregnancy or child birth is 1 in 39 persons, compared to the global average of 1 in 180; compare to countries like China, Singapore, Hong Kong where a woman's risk of maternal death is 1 in 3,800. In Nigeria, 40,000 women die during pregnancy or childbirth each year, and another 1 to 1.6 million suffer from serious and permanent disabilities from pregnancy- and birth-related causes annually. More so, majority of infant mortality often occur within the first week of newborn babies mainly due to complications during pregnancy, delivery and post-delivery; reflecting the intimate link between newborn survival and quality of maternal care during and after pregnancy.

Another important indicator of health outcomes is the average life expectancy (at birth) which refers to the average number of years a newborn is expected to live if mortality patterns at the time of birth remains constant in the future. It is the average-period that a person is expected to live as determined taking account of current economic situation. This also reflects the overall mortality level of a population, and summarizes the mortality pattern that prevails across all age groups. It also indicates the number of years a newborn infant would live if patterns of mortality prevailing for all people at the time of birth were to stay the same throughout his life. Hence, it is an important index of long life and quality of living [11].

Table 2 reveals average life expectancy at birth of Cote d'Ivoire, Ghana, South Africa, Rwanda, and Nigeria. The average life expectancy at birth (total) in Nigeria increased marginally from 46 years in 1995 to about 53 years in 2015, while Rwanda's life expectancy increased from 31 years to about 65 years during the same period. In comparison, average life expectancy at birth in Nigeria is lower compared with Ghana and South Africa.

There is also evidence to this effect from selected recent studies $[12,13]$ that the health conditions of the poor tend to be worse than those of non-poor due to factors such as, health financing, material, social or psychic deprivation, and socio-economic factors. In the same vein, Anderson and Marmot [14] suggest that those who live longer lives (and suffer less from ill-health and morbidity) often contribute to economic outputs Hence, average life expectancy at birth can be regarded as a critical factor for economic prosperity, and clear indicator of health outcomes [15].

Another important indicator of health outcomes consists of the prevalence of other deadly diseases, such as; malaria, cholera, acute hepatitis E, Lassa fever, stroke, hypertension, polio, typhoid, meningitis, and all forms of cancer which are major characteristics of many households, indicating that health outcomes in Nigeria is generally poor. These measures are seen as indicator of households' health outcomes. Theoretically, the principal-agent theory that has its roots in information economics is important to this comparative analysis. The theory arises when two (or more) parties with one, designated as the agent, acts on behalf of, or serve as representative for other, the public, in a particular domain of decisions [16]. Principal-agent relationship can be characterized by principals or public (ill-informed) and agent (informed individual).

Empirically, numerous studies have linked changes in infant and maternal mortalities to low health care financing, which results to inadequacy of health equipment, infrastructure, and resource use at hospital, managed care; and educational status of mothers. Barenberg, Baru and Soylu used a panel dataset of Indian states between 1983 and 2012 to examine the effect of public health expenditure on infant mortality in India. After controlling for other relevant covariates like per capita income, female literacy, and urbanization; the authors found that an increase in public health expenditure by $1 \%$ is associated with 
a reduction in the infant mortality rate by about 8 infant deaths per 1,000 live births.

However, Hartwig, Sparrow, Budiyati, Yumma, Warda, Suryahadi and Bedi exploit the variation in the design of health care financing in Indonesia to assess its effect on maternal care from 2004 to 2010. The analysis was based on district pseudo-panel, combining data from a unique survey among District Health Offices in Indonesia. Their finding show that district schemes contribute to an increase in antenatal care visits and the probability of receiving basic recommended antenatal care services, and a decrease in home births, especially for households that fall outside the target group of the national health insurance programs.

Issa and Ouattara [17] disaggregate health care financing into public and private. Employing a panel data on 160 countries their results show a strong negative relation between health financing and infant mortality rates. Similarly, Alves and Belluzzo investigate the determinants of mortality rates in Brazil for the period 1970 to 2000. The study estimate panel data models using census data and indicate that high mortality rates in Brazil can be explained by the level of education, sanitation and poverty.

Similarly, the effects of government financing of health expenditures, health insurance coverage and other factors on children and mothers' health outcomes are examined by Berger and Messer [18] employing health production models estimated using 1960 to 1992 data across 20 OECD countries. Their finding shows that increases in the publicly financed share of health expenditures are associated with increases in mortality rates. The authors therefore conclude that, as countries increase the level of their health spending, they may want to avoid increasing the proportion of their expenditures that are government financed. Furthermore, Or [19] explores the determinants of variations in mortalities rates across 21 OECD countries between the period of 1970 and 1995, and found weak statistical significant relationship between per capita health expenditure and mortalities rates. As he observes, the absence of a strong statistical relationship may be due to model specification or may reflect the fact that at high levels of population health, the returns to increase in health spending are small.

In Africa, a recent study by Adepoju [20] examines the differentials in mortalities rates across socio-economic, demographic and selected health characteristics. The study employing the 2008 National Demographic and Health Survey data which were collected using three well-structured questionnaires (household, women's and men's questionnaires). Results show that child mortality rate was highest among illiterate mothers, mothers without a source of income, under aged women (less than 20 years) and among fathers whose primary livelihood lie in agriculture and fathers without means of incomes.

However, Osawe [21] investigates factors that affect the rate of mortality among infants under one year of age using panel data sets from the World Bank's World Development Indicator database from 2000 to 2009 for 53 African countries. The results obtained after correcting for endogeneity showed that fertility rate significantly affect infant mortality rate in a positive way. Similarly, Gross Domestic Product (GDP) per capita as a proxy for income, public health expenditure as a percentage of GDP, prevalence of HIV and the participation of adult female in the labour force significantly affect infant mortality rate (IMR). In another study, Adetoro and Amoo [22] used data from Nigerian Demographic Health Survey (NDHS) dataset to investigate the determinants of child (aged 0-4 years) mortality in Nigeria. The binary logistic regression techniques employed reveals that education of both parents and occupation of mothers were found statistically significant to reduction in childhood mortalities rates.

Similarly, Godson and Mojekwu [23] used data from the Nigerian Demographic and Health Survey (NDHS) 2008 and the annual abstract of the National Bureau of Statistics (NBS) to evaluated environmental determinants of child mortality in Nigeria. The study employed multiple regression techniques, and the combination of the household environmental factor significantly predicted infant mortality with the immunization/household dwelling infrastructure/ low polluting fuel factor significantly contributing to high childhood mortalities. In addition, Mojekwu and Ajijola [24] use multivariate logistic regression techniques. Antai, employs the multilevel logistic regression model, but Ozumba and Nwogu-Ikojo [25] applied multiple regressions techniques with autocorrelation adjustment to estimate mortality, while Ogunjuyigbe [26] combine univariate and bivariate analysis to calculate mortality indices for woman. All these studies find demographic, socio-economic (age, sex, level of education, income level, and occupation) and environmental factors (source of drinking water, and sanitation facilities) to be significantly related to high infant and child mortalities rates in Nigeria.

Baird et al. [27] investigated the relationship between health expenditures and children mortality in developing countries. Their findings reveal that there is a large, negative association between per capita GDP and infant mortality- on average, a $1 \%$ decrease in per capita GDP is associated with an increase in mortality of between 0.24 and 0.40 infants per 1,000 children born. Female infant mortality is more sensitive than male infant mortality to economic fluctuations, especially during negative shocks to GDP. In developing countries, approximately $30 \%$ of all deaths occur to children under the age of five, compared to less than $1 \%$ in rich countries [28-32].

Further empirical evidence on the relationship between health care financing (proxy by per capita public health expenditure), underfive mortality rates and crude death rates has provided by Azmat by using cross-country data from seven Pacific Island countries, which argued that that per capita health expenditure is an important factor in determining health outcomes [33-35]. The results suggest that a $10 \%$ increase in per capita health expenditure would lead to an approximate $6.6 \%$ reduction in infant mortality rate. Therefore, this study presents comparative analysis of health sector performances in Nigeria with other African countries.

\section{Method and Data Sources}

The method of analysis for this study is comparative analysis through trends and descriptive statistics of health indicators and health financing in Africa countries. The paper would source all variables (health spending) from World Development Indicators databases. In the paper, percentages of GDP on health spending (both private and public) was proxy for health sector performance and outcomes in Nigeria compared to other countries from different regions in Africa. Comparatively, the study considered Tunisia (for North Africa), Ghana (for West Africa), South Africa (for Southern Africa), Rwanda (for East Africa), and Central Africa Republic (for Central Africa).

\section{Results}

The trends and comparative analysis of health spending in africa

The trend analysis of Figure 1 depicts that the direction of African 
governments spending on health (as percentage of total Gross Domestic Product). It's also indicates priority and commitment in terms of resources devoted to health sector. Comparatively, the proportion of public health spending as percentage of GDP in Nigeria is the lowest with only $9 \%$, while for Ghana (in the same West Africa region with Nigeria) and Tunisia approximately $21 \%$ and $39 \%$ of the GDP was spend on health sector respectively in 2014.

Figure 2 further revealed that the public health financing (as a percentage of total expenditure) across countries (in different regions) in Africa (Nigeria, Tunisia, Ghana, South Africa, Rwanda, and Central Africa Republic) indicates disparities in health expenditure. It was also shown that Nigeria spent far less compared to other Africa countries. For instance, the percentage of public health spending to the total expenditure in Nigeria was merely $8 \%$, while Central Africa Republic, Tunisia, and South Africa spent $14 \%$ of the total spending on health sector in 2014.

\section{Conclusion and Policy Recommendations}

The trend analysis (as presented in Figures 1 and 2) show that Nigeria health sectors might lag behind in terms of health sector financing; this probably might be accountable for poor health indicators in the nation. For instance, Nigeria has the third highest infant mortality rate in the world after India and Pakistan; while in every single day, the nation also loses an estimated of 2,300 under-five year olds children which also makes her the second largest contributor to under-five mortality rates worldwide after Republic of Chad.

Conversely, other countries from Africa such as Tunisia, Ghana, South Africa, Rwanda, and Central Africa Republic committed far more resources and gave high priority to health sector financing compared to Nigeria. The impact of those investments has directly culminated to low life expectancy and high mortalities. Therefore, the comparative study suggests that Nigeria needs to strengthen efforts

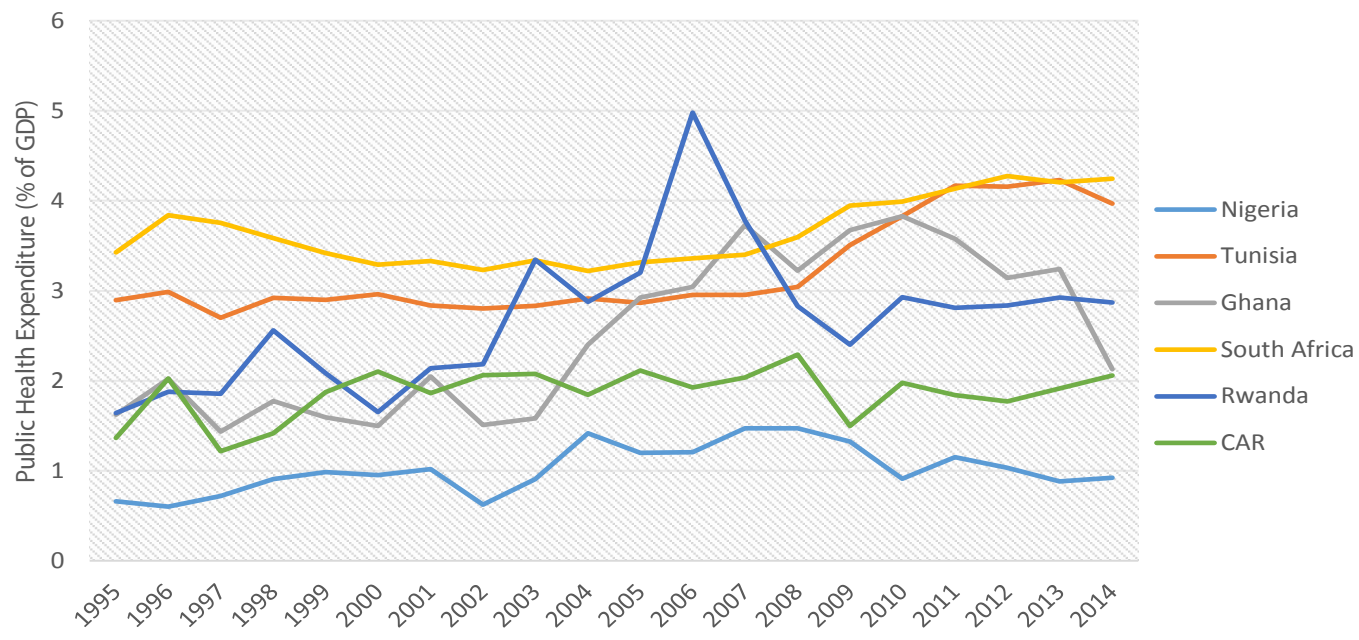

Source: Compiled from World Development Indicators (2017).

Figure 1: Public health expenditure (\% of gross domestic product) in Africa.

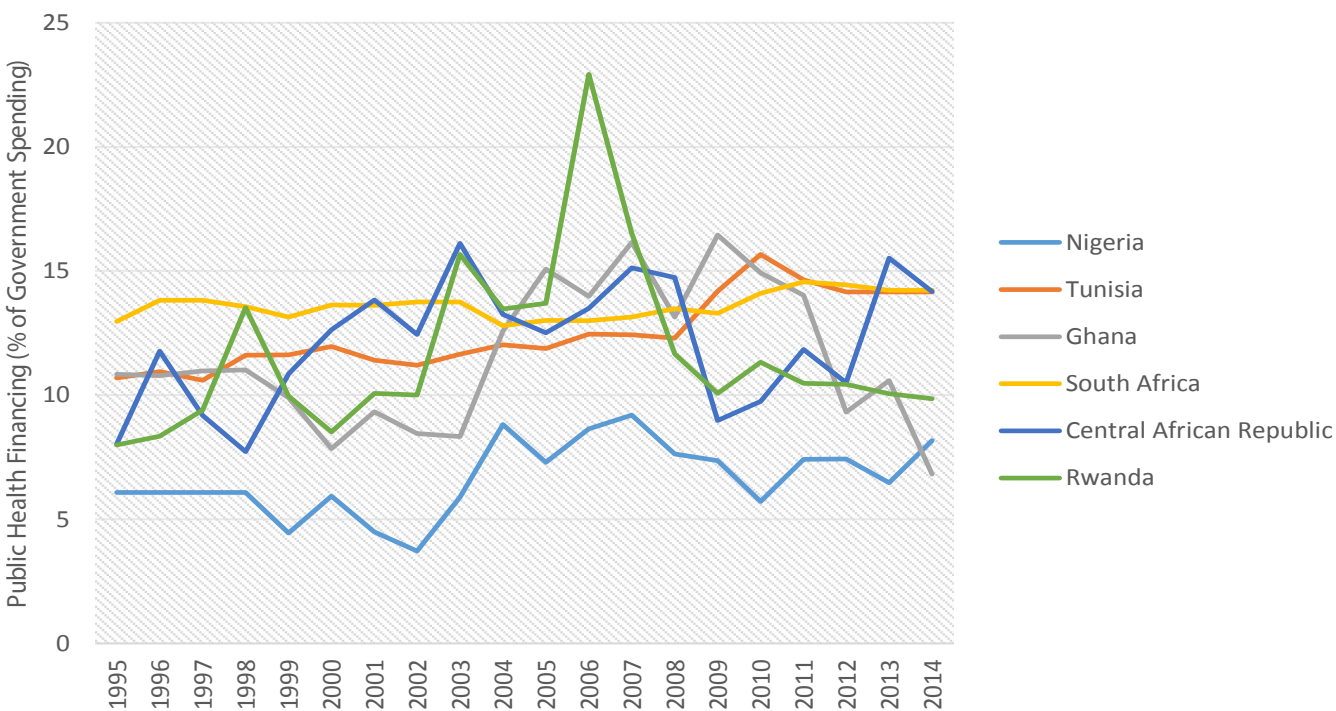

Source: Compiled from World Development Indicators (2017)

Figure 2: Public health expenditure (\% of total expenditures) in Africa. 
Citation: Timothy PO (2018) Needs for Restructuring the Health Sector Financing in Nigeria: An Exploratory Comparative Study. Int J Econ Manag Sci 7: 526. doi: 10.4172/2162-6359.1000526

Page 5 of 5

towards improving health indicators through restructuring her health sector financing.

\section{References}

1. UNICEF (2016) Why income inequalities matter for young people's health: A look at the evidence. Working Paper-2016-06.

2. World Bank (2017) World Development Indicators. Washington DC: World Bank.

3. WHO (2017a) Fact Sheet on Cholera. World Health Organization, Geneva, Switzerland.

4. WHO (2017b) Levels and Trends in Child Mortality Report. Geneva, Switzerland.

5. United Nations Development Programme (2016) UNDP Nigeria Annual Report for 2016. UNDP.

6. UNICEF/WHO (2010) Progress on Sanitation and Drinking Water. WHO/ UNICEF Joint Monitoring Programme Report.

7. Novignon J, Nonvignon J, Arthur E (2015) Health status and labour force participation in Sub-Saharan Africa: A dynamic panel data analysis. African Development Review 27: 14-26.

8. Adedini SA (2013) Contextual Determinants of Infant and Child Mortality in Nigeria, an unpublished PhD Thesis, University of the Witwatersrand, Johannesburg, South Africa.

9. Karimo TM, Krokeyi WS, Ekainsai SZ (2017) Financial burden associated with ill-health: Evidence from the Elderly Population in Nigeria. Equatorial Journal of Social Sciences and Human behavior 2: 25-43.

10. United Nations Development Programme (2014) 2014 Human development trends by indicator.

11. Grepin KA, Bharadwaj P (2015) Maternal education and child mortality in Zimbabwe. Journal of Health Economics 44: 97-117.

12. Ou HC, Yang T, Wang J, Hwang, Wu J (2016) Life Expectancy and Lifetime Healthcare Expenditures for Type 1 Diabetes: A Nationwide longitudinal cohort of incident cases followed for 14 years. Value in Health 19: 976-984.

13. Linden M, Ray D (2017) Aggregative bias-correcting Approach to the HealthIncome relationship: Life-Expectancy and Gross Domestic Product per capita in 148 countries (1970-2010). Economic Modelling 61: 126-136.

14. Anderson MV, Rutherford MD (2012) Cognitive reorganization during pregnancy and the postpartum period: an evolutionary perspective. Evolution Psychology 10: 659-687.

15. Bakkeli NR (2016) Income inequality and health in China: A panel data analysis Social Science and Medicine 157: 39-47.

16. Ross SA (1973) The economic theory of agency: The Principal's Problem. National Science Foundation 63: 134-139.

17. Issa H, Ouattara B (2005) The Effect of Private and Public Health on Infant Mortality Rates: Does the Level of Development Matters.

18. Berger MC, Messer J (2002) Public financing of health expenditures, insurance, and health outcomes. Applied Economics 34: 125-139.
19. Or Z (2001) Exploring the effects of health care on mortality across OECD countries. Labour market and social policy papers 46, OECD Directorate for Employment. Labour and Social Affairs.

20. Adepoju AO (2015) Differential pattern in child mortality rate in rural Nigeria Annual Research \& Review in Biology 7: 309-317.

21. Osawe OW (2014) Determinant of infant mortality rate: A panel data analysis of African countries. developing country studies 4: 111-115.

22. Adetoro GW, Amoo EO (2014) A Statistical analysis of child mortality: Evidence from Nigeria. Journal of Demography and Social Statistics 1: 110-120.

23. Mesike CG, Mojekwu JN (2012) Environmental determinants of child mortality in Nigeria. Journal of Sustainable Development 5: 65-75.

24. Mojekwu JN, Ajijola LA (2011) Developing a model for estimating infant mortality rate of Nigeria. Journal of Research in International Business and Management 1: 164-170.

25. Ozumba BC, Nwogu-lkojo EE (2008) Avoidable Maternal in Enugu, Nigeria. Public Health 122: 354-360.

26. Ogunjuyigbe PO (2004) Under-Five Mortality in Nigeria: Perception and Attitude of the Yoruba towards the Existence of Abiku. Demographic Research 11.

27. Baird S, Friedman J, Schady N (2009) Aggregate income shocks and infant mortality in the developing world. The Review of Economics and Statistics 93: 847-856.

28. Ross DS, Venkatech R (2015) An Empirical Study of the Factors Influencing Quality of Healthcare and Its Effects on Patients' Satisfaction. International Journal of Innovation Research in Science, Engineering and Technology 4 54-59.

29. World Health Organization (2006) Working Together for Health: The World Health Report.

30. Howlader MR (2014) An Estimation of Health Production Function of Bangladesh. Directorate of Secondary and Higher Education, Dhaka.

31. Lavallee E, Mireille R, Rouband F (2008) Corruption and trust in politica institutions in sub-Saharan Africa, Dial development Institutions and analysis de long term DT/2008-07.

32. Jinadu MK, Olusi SO, Agun JI, Fabiyi AK (1991) Childhood diarrhoea in rura Nigeria: Studies on prevalence, mortality and socio-environmental factors. Journal of Diarrhoea Diseases Research 9: 323-327.

33. Pillai VK, Maleku A, Wei $F$ (2013) Maternal mortality and female literacy rates in developing countries during 1970-2000: a latent growth curve analysis. International Journal of Population Research.

34. Rodgers GB (2002) Income and inequality as determinants of mortality: An international cross-section analysis. International Journal of Epidemiology 31 533-538.

35. Romer PM (1990) Human Capital and Growth: Theory and Evidence. CarnegieRochester Conference Series on Public Policy 32: 251-286. 